American Journal of Infectious Diseases 2 (2): 80-89, 2006

ISSN 1553-6203

(c) 2006 Science Publications

\title{
Interventions and Patterns of Risk in Adolescent HIV/AIDS Prevention
}

\author{
${ }^{1}$ Robert M. Malow, ${ }^{1}$ Rhonda Rosenberg, ${ }^{2}$ Geri Donenberg and ${ }^{1}$ Jessy G. Dévieux \\ ${ }^{1}$ Florida International University ${ }^{2}$ University of Illinois at Chicago
}

\begin{abstract}
Mid-way through the third decade of experience in preventing HIV/AIDS among adolescents, behavioral interventions and outcomes for high risk subgroups have generated evidence extremely instructive for navigating future priorities in reducing transmission risk behavior. Youth who abuse alcohol or drugs, who are detained or incarcerated, or have mental health co-morbidity such as externalizing disorders, represent the most significant challenge to current and future efforts to control the epidemic among the adolescent population. Although there is no unambiguous, standard intervention approach with adolescents, patterns of risks and outcomes with these subgroups are instructive in the critical priority of creating more sustainable gains with our HIV prevention resources. This article provides a synthesis of the evidence with these subgroups, discusses important limitations and difficulties in the current intervention science and highlights promising directions for the next generation of effort in reducing adolescent HIV-related sexual risk behavior. Because individual-level interventions have had only modest effects, a key current emphasis within the field is to develop multilevel interventions with a more ecological or contextual focus. We review various pragmatic responses that acknowledge this priority and the debt owed to individual-level intervention work with adolescents.
\end{abstract}

Key words: HIV prevention, sexual risk behaviors, drug and alcohol abuse, juvenile offenders

\section{INTRODUCTION}

AIDS cases among adolescents continue to rise in the U.S. after last dropping 1997-1998, according to the most recent official surveillance ${ }^{[1]}$. Although HIV incidence data are not available according to demographic categories of age, race, ethnicity and gender, it is clear from reported AIDS cases that black adolescents carry the majority of the burden. Among adolescents (i.e., 13-19 years old), 73\% of the cases are black $^{[2]}$. The foremost risk factors for American adolescents are heterosexual contact, gay male sexual contact, sexually transmitted infection (STI), substance abuse, mental health problems, childhood sexual abuse, involvement in the criminal justice system, being outof-school and living in poverty ${ }^{[3]}$. The most dominant transmission category among adolescents, as tracked by the CDC, remains male-to-male sexual contact $(43 \%)^{[1]}$, although female risk due to heterosexual transmission is rising, particularly among minorities ${ }^{[3]}$. Among adolescents, $66 \%$ of female AIDS cases can be attributed to heterosexual contact as compared to $8 \%$ of male cases ${ }^{[1,3]}$.

The urgency of adolescent HIV/AIDS in the U.S., however, is primarily due to what is known of sexual risk profiles, especially among high-risk subgroups such as those with alcohol or drug (AOD) abuse problems, juvenile offenders and those with mental health problems and externalizing behaviors. The risk behaviors of these subgroups pose a serious public health concern because of the chronicity that they potentially represent: the relapse common to AOD abuse, the recidivism of being an offender and the developmental complications of having mental health and externalizing behavioral problems $\mathrm{s}^{[4,5]}$.

These subgroups present the following HIV risk profile: 1) extremely disproportionate STI rates compared to average counterparts; 2) pervasive HIV/AIDS risk behavior, including prevalent multiple partner behavior and unprotected sex); 3) early initiation to sex; and 4) disturbing rates of AOD abuse and use proximate to sex. Almost 25\% of American high school students have reported AOD use prior to sex in a national survey conducted by the $\mathrm{CDC}^{[6]}$. In a study of incarcerated youth, $24.8 \%$ of adolescent males reported AOD use before engaging in sexual activity and $46.3 \%$ reported that alcohol was available the majority of the time at social gatherings ${ }^{[7]}$. AODabusing adolescents frequently evidence low condom use and more sexual partners ${ }^{[8]}$; more STI ${ }^{[9]}$; less HIVrelated knowledge and lower perceived susceptibility to HIV infection ${ }^{[10]}$; lower self-efficacy and perceived peer norms regarding safer sex practices; psychopathology (e.g., conduct disorder, impulsivity, affect lability, impaired attention and judgment $)^{[4,11]}$; and prostitution for money, drugs, food and shelter ${ }^{[12]}$.

Corresponding Author: $\quad$ Dr. Robert M. Malow, Florida International University, College of Health and Urban Affairs, Stempel School of Public Health, AIDS Prevention Program, Biscayne Bay Campus, AC1-260, 3000 NE $151^{\text {st }}$ Street, North Miami, FL 33181 
Moreover, patterns of risky sexual behavior that emerge in adolescence appear to persist into young adulthood $^{[8]}$.

Among juvenile offenders, gonorrhea incidence has been reported to be 42 times higher among confined males compared to average male adolescents and 152 times higher among confined females ${ }^{[13,14]}$. Possibly $95 \%$ of such youth may be involved in 3 or more HIV/AIDS related risk behaviors, with $65 \%$ in 10 or more ${ }^{[15]}$. Over half of female juvenile offenders as young as 10-13 may already be sexually active, rising to almost $95 \%$ for those 16 and older. The CDC has noted that juvenile offenders comprise most of the outof-school adolescent grouping, in which reports of sexual intercourse are almost $25 \%$ higher than among in-school counterparts ${ }^{[14]}$. AOD use hovers around $90 \%$ for alcohol or marijuana among adolescent offenders, with as many as $30 \%$ having had unprotected sex when intoxicated or under the influence of drugs ${ }^{[15]}$.

The American Academy of Pediatrics ${ }^{[16]}$ has noted that between $20 \%$ and $60 \%$ of adjudicated adolescents could be diagnosed as having a conduct disorder, according to a 1992 report. The range may be $2 \%-17 \%$ for personality disorders and $32 \%-78 \%$ for affective disorders. Most studies of the relationship between externalizing psychopathy and HIV risk, however, have been conducted with adult populations." Generally higher levels of antisocial symptoms have been associated with increased HIV risk and seroprevalence rates $^{[17-20]}$. A subtype of psychopathic personality $\operatorname{disorder}^{[21,22]}$, Antisocial Personality Disorder (APD), has been linked among AOD abusers to condom nonuse, multiple sex partners, prostitution, sexually transmitted diseases, unfavorable HIV risk attitudes, injection drug use, early onset injection drug use, and needle sharing ${ }^{[19,20,23-29]}$. While Abbott et al. ${ }^{[30]}$ found no association between APD and HIV risk behaviors, the significance of the role of such externalizing psychopathologies has continued to be affirmed, particularly in comorbid samples of AOD abusers ${ }^{[31,32]}$. APD has been characterized by impulsivity, low thresholds for erotic discharge, recklessness in the safety of self and others and aggressive reactivity to social norms ${ }^{[33]}$. In addition, approximately two-thirds of AOD abusers entering treatment present with a DSM-III or IV personality disorder diagnosis, with APD the most common ${ }^{[17]}$. In a recent study by Bryan et al. ${ }^{[34]}$ lifetime conduct disorder (by meeting at least 3 DSM-III-R criteria) was found among $99 \%$ of a mandated treatment sample of AOD abusing male adolescent offenders.

Depressive disorders and symptoms are highly prevalent during adolescence, also, particularly among AOD-abusing youth ${ }^{[35]}$. Adolescents with affective disorders remain understudied, even though they evidence extremely high levels of risky sexual and substance abuse behavior ${ }^{[36]}$. Many such adolescents demonstrate cognitive deficits, such as poor executive function and reality testing and dysfunctional perceptions of interpersonal interactions and relationships ${ }^{[37]}$. They also exhibit high levels of poor emotion regulatory skills. A co-occurrence of psychiatric disorders with substance abuse may further compound these deficits ${ }^{[38,39]}$ and interfere with HIV prevention efforts. Population-based studies reveal a formidable problem, with prevalence estimates of comorbid psychiatric disorders in the range of approximately one-half to three-quarters among samples of AOD abusing adolescents ${ }^{[40]}$.

Adolescent prevention intervention science: The challenges of HIV/AIDS for these subgroups are a reminder to the research community that the essence of adolescence is that their development is still incomplete. Thus, maturational and development processes are ongoing and adolescents may not yet possess sufficient knowledge, motivation and skills to implement safer sex behaviors. Moreover, interactions with peers over sexual relationships and drug use require effective communication skills and the negotiation of powerful emotional terrain ${ }^{[41,12]}$. Failures in development, which include capacities to connect emotional and cognitive experience, often continue into adulthood. Basic scientific research reinforces this clinical observation, even in the case of AOD abuse. As reported in recent neuroscientific research, addiction itself may best be conceived as a developmental disorder during adolescence-as an exploiter of changes in cognitive functioning that mark the transition to adulthood ${ }^{[42]}$. At the very least, it is clear that the transition to adulthood for those with continuing substance use and mental health problems is decidedly marked by an increased vulnerability that includes HIV transmission risk behavior ${ }^{[8]}$.

A recent review of adolescent HIV/AIDS prevention interventions in North America ${ }^{[43]}$ revealed gains in the ability to address the special vulnerabilities of adolescents. However, at least three important caveats exist. Most important is the tendency for effects to diminish over time, despite significant short-term improvement (e.g. 30-90 days) effects ${ }^{[9,11,44,45]}$. This problem is complicated further by the use of small convenience samples and short follow-up periods because of difficulties in recruiting and retaining large probability samples of adolescents.

Second, most data are based on self reports and threats to validity may introduce error, such as lack of insight, perceptual distortions, intentional or unintentional misrepresentation, transitory drug effects (withdrawal), drug-dependent learning, variations in retrospective reporting durations, or characteristics associated with the research environment or implementation ${ }^{[46]}$. This is particularly true among drug abusing adolescents, those in psychiatric care or involved in the criminal justice system ${ }^{[46,47]}$. Validity coefficients for adolescent offenders' self-reported drug 
use are among the lowest ${ }^{[47,48]}$. For example, urine testing has confirmed that adolescent arrestees often succeed in concealing drug use during interviews even under the best conditions. And after factors such as response style, interviewer characteristics, social desirability and the interview setting are taken into account, there remain others to consider: type of drug; whether the person is assigned to a treatment or comparison group; whether the interview occurred at intake, in treatment, or post-discharge; and the severity of the respondents' drug use. One useful validation strategy for self-reported data is to include toxicological measures. However, dedicated research on this issue is still needed to determine actual feasibility, cost and effectiveness for different adolescent subpopulations.

Another surrogate strategy for validating selfreported sexual activity and protective behavior is to include measures of STIs. Demonstrating a meaningful reduction in HIV/AIDS transmission based on incident HIV infections requires both large samples and a high initial incidence rate in the target population. HIV seroconversion can take up to 6 months after exposure and infection; therefore, a negative HIV antibody test may not accurately reflect the presence or absence of a newly-acquired HIV infection. In addition, because HIV serostatus can represent infections that occurred six months to a dozen years earlier, it does not necessarily reflect recent change or lack of change in risk behavior. Given these limitations, a more practical alternative is to measure the incidence of new STIs in the population of interest. Because the rate of many STIs is higher than that of HIV among youth, STI incidence provides better information about the presence of recent high-risk sexual activity among AOD abusing adolescents.

An alternative assessment procedure involves DNA amplification techniques. This method has been increasingly recommended ${ }^{[49]}$ because it has greater diagnostic sensitivity than traditional culture-based tests and does not require a genital exam ${ }^{[49,50]}$. This is important for individuals who do not wish to consent to a physical exam. Bacterial STIs (e.g. chlamydia and gonorrhea), trypanosome and syphilis are the preferred STIs to measure as indicators of HIV risk behavior because they can be treated effectively, allowing subsequent new infections to be detected and then utilized as signifiers of unsafe sexual behavior. It is important to note that viral STIs such as HPV or HSV-2 are not useful biological measures since there is no cure for these viruses. Gonorrhea and chlamydia are the most common STI markers of HIV risk behavior because they are particularly prevalent in adolescents, although more so with females than with males ${ }^{[9]}$. Because STIs are not a perfect marker of the level of sexual activity, another recommendation is to "triangulate" information on STI occurrence with other sources of information, such as self-reports and community prevalence patterns, to gain the most confident view of post-intervention changes. Recent evidence suggests that self-reports are most accurate when subjects are aware that their responses will be corroborated by other sources of information ${ }^{[46,51]}$.

A final sobering caveat to existing prevention interventions for adolescents is the substantial unexplained variance in adolescent HIV risk behavior following the intervention. Contextual factors, ranging from individual to situational variables, may complicate the interpretation of results and moderate the effect of interventions, particularly in high risk groups. Gender and age, for example, are significantly associated with HIV risk behavior $\left.{ }^{[11,}{ }^{52}\right]$ as well as underlying psychological causal factors, such as impulsivity, sensation-seeking or some general psychopath deviancy factor $^{[5,53]}$. In the case of AOD abuse, the empirical literature on its relationship to sexual behavior has varied across groups, depending on psychological, situational and behavioral factors ${ }^{[54]}$. This has occurred even with the use of similar methodologies to study this relationship, such as using event related or situation covariation methodology. While research has confirmed the complexities introduced by intrapersonal contextual factors, we are just at the beginning of understanding how to respond to them.

The same is true of social ecological factors. Perhaps one of the most innovative observational studies as we neared the two-decade marker of the HIV/AIDS epidemic was the "broken windows" research by Cohen et al. ${ }^{[55]}$. Their constructed index of neighborhood health was more highly associated with gonorrhea rates than the customary poverty index. Though this study could only isolate a correlation and not a causal effect, it was a graphic wake-up call to the HIV prevention research community in the United States, which had not yet managed to systematically pull the social context off the back burner. Shoveller et al.'s ${ }^{[56]}$ recent review concentrated on assessing progress on this issue and concluded that nearly all adolescent STI or HIV interventions continue to focus on individual risk. Further, even when social contextual factors are introduced, they are measured at the individual level. Not only were there no truly structural adolescent interventions that included community providers, lawmakers and policymakers and community leaders, neither were there social network interventions. Exposure to high-risk networks has been identified as an individual risk factor for both substance abuse and sexual risk behavior. Moreover, association with highrisk peers may be predictive of relapse behavior; and in fact, the power of such social contexts may be the single most determining factor in the decay function of risk reduction interventions. As Moos ${ }^{[57]}$ makes clear, social contexts will limit (as well as sometimes enhance) the capacity of individuals to make use of interventions.

However, it is important to also view prevailing interventions based on the epidemiology of 
HIV/AIDS and the scientific methodology. Because HIV transmission is largely preventable through behavioral change, the attention of the intervention community has been primarily anchored in developing testable theories of HIV risk behavior and securing prevention trials that produce reliable predictors and replicable designs. This approach is rooted in testing theoretically grounded models in manual-based interventions to maximize chances for a cumulative process of understanding how to intervene. The result has been a tendency toward small-group behavioral interventions with multiple sessions and intensive interaction as the general format. Critics, including those dissatisfied with the rapid decay of treatment effects and the largely unexplained variance of such models, increasingly have challenged this approach for being too narrow in its reliance on the individual, rational decisionmaking framework and not sufficiently attentive to the social and institutional context of health and human behavior ${ }^{[58]}$.

In contrast, others such as Rapkin and Dumont ${ }^{[59]}$ argue that group interventions allow for the methodical investigation of important contextual factors and the influence of the social, peer and institutional norm dimensions. Benotsch and Kalichman ${ }^{[60]}$ have noted that more than one national review panel has endorsed the effectiveness of the small-group HIV intervention approach and affirmed the scientific appeal of being able to manualize and standardize such designs. Manualized group interventions acknowledge the limitations of community providers and permit adaptation to new populations, including tailored versions to fit the needs of subgroups while remaining grounded in testable theory. The growing recognition of health disparities, in particular, has highlighted the need to identify and differentiate the most effective and predictive components for addressing the populations hardest hit by HIV/AIDS. It is clear that group HIV prevention interventions have been able to affect the aggregate index of sexual behavior outcomes, including specific targets such as condom use, frequency of unprotected sexual intercourse and number of sexual partners-all behaviors with recognized links to STI risk among adolescents ${ }^{[11]}$.

This approach also has had significant impact on many of the predictors and correlates of risk behavior, including self-efficacy, intentions and attitudes. Studies of mediators have identified characteristics at the intervention and participant levels that may influence the magnitude and direction of effects. Attention has increasingly focused on indicators of the sexual dyad or partnership, and relationship status has been identified as a mediator of condom use ${ }^{[61,62]}$. The analysis of mediators has allowed the identification of affective attitudes as a key mechanism of change in group interventions, specifically affective attitudes toward condoms as well as self-efficacy in condom use.

The empirical literature also shows the superiority of testable, theory-based interventions to atheoretical approaches in producing desired effects. A comprehensive review of 40 HIV risk-reduction group interventions ${ }^{[63]}$ reported that those investigations that cited a culturally sensitive, theoretical framework were the ones most likely to demonstrate target effects among adolescents. Further, evaluations of school-based AOD abuse prevention programs have pointed to the intense, interactive framework that characterizes smallgroup interventions as an important medium for producing change. Change is often modest, though, suggesting that the context of high-risk adolescents - both as individuals and as members of a group - is still not being fully addressed ${ }^{[64]}$.

While interventions are often said to be guided by theory, an alternative view is to consider theoretical models as being guided by the small-group intervention approach. In the case of the work by Fisher and Fisher, they and their colleagues have typically utilized the small-group intervention approach more as a means rather than an end, in order to understand how their theory, the Information-Motivation-Behavioral skills (IMB) model of HIV risk behavior, can help produce more tailored interventions sensitive to the intrapersonal constraints and social ecology of risk populations (http://www.chip.uconn.edu/ and http://digitalcommons.uconn.edu/cgi/viewcontent.cgi?a rticle $=1001 \&$ context=chip_docs for Fisher $\&$ Fisher's 1992 detailed discussion of risk behavior theories in "Changing AIDS-Risk Behavior"). Fisher et al. ${ }^{[65]}$ report results of a study comparing three IMB type interventions with inner-city minority high school students: classroom based (delivered in regular classrooms by their teachers) versus peer-based (utilizing peers outside the classroom) versus a classroom/peer combined intervention. Only the classroom based intervention resulted in sustained changes in HIV risk behavior at the twelfth month follow-up. The limitation of the study was that it was quasi-experimental, in that schools were not randomized. However, because it emerged out of cumulative work with the IMB model, its credibility is greater in being able to affirm the potential impact of more social ecological designs on the motivation of adolescents and their capacities to integrate HIV prevention information, intentions and behavioral skills and translate these into action and protective behavior.

Affective and social ecological dimensions in sustaining change in high risk adolescent subgroups: The IMB model's prominence in basic prevention science underscores the continued emphasis on individual cognitive factors as determinants of risk ${ }^{[66]}$, 
yet most scholars recognize the broader social and ecological context of behavior, especially among youth $^{[37]}$. More recently, researchers have begun to explore a variety of ecological dimensions that may explain adolescent risk taking and risk reduction, with attempts to determine the unique mechanisms for specific populations ${ }^{[37]}$ (such as youth in psychiatric care). Among the risk and protective processes that have been implicated in adolescent risk are family functioning, peer and partner relationships, environmental context and youths' personal attributes, including value on health, achievement orientation and emotion regulation. Particular emphasis has been applied to those factors that can be targeted in prevention and intervention. The broader ecological factors combined with individually-focused cognitive mechanisms implicated by the IMB model are likely to provide a more comprehensive understanding of adolescent risk and prevention behavior than individual, interpersonal, or environmental factors alone ${ }^{[37]}$. This recognition has stimulated new research intended to explain risk more fully and sustain treatment effects over a longer period of time.

Family context, in particular, has emerged as a prominent focus of basic and prevention research in adolescent HIV risk. Families provide the first and most visible context for sexual and interpersonal relationship behavior $^{[67]}$. Parents are children's primary sex educators and they can sustain prevention messages long after the formal intervention ends. Affective and instrumental parenting characteristics are consistently linked to increased and decreased risk, including parental warmth, a close parent-child relationship, parent-teen communication and parental monitoring, control and supervision, ${ }^{[37,68-71]}$. Many of the same family characteristics can be traced to other problem behaviors during adolescence, such as psychopathology (e.g., depression, anxiety, disruptive behavior disorders) and alcohol and drug use ${ }^{[72-74]}$. Close parental monitoring and supervision, especially for teens living in high-risk contexts (e.g., significant crime and poverty), can effectively protect against engagement in risk behavior and exposure to situations where sexual activity is possible ${ }^{[75,76]}$. Likewise, parental warmth and support and a strong parent-child relationship is related to less adolescent risk taking and low levels of alcohol and substance use and psychopathology. Some research suggests that the most effective family context to prevent risk behavior is high control in the context of high parental warmth ${ }^{[77]}$. The third family factor consistently linked to adolescent risk is parent-teen communication. Effective, open and comfortable communication, particularly about sexual topics, is predictive of less risk taking, greater health promoting behavior (condom use, less frequent sexual behavior) and more communication about sexual topics with sexual partners ${ }^{[78,79]}$. Taken together, these familyrelated factors play an important role in reducing adolescent risk and possibly sustaining intervention effects $^{[80]}$.

The development, influence and negotiation of peer and partner relationships reflect normal developmental processes important during adolescence. Despite the continued and powerful impact of families on adolescent behavior, peers and romantic partners take on new roles and influence in the lives of youth, affecting their decision making and behavior ${ }^{[81-83]}$. Ample evidence links perceptions of peer norms, beliefs and attitudes about risk taking to adolescents' own risk behavior. Yet other factors also influence youths, including a need for intimacy, fear of rejection and the desire for acceptance ${ }^{[84]}$. During the transition to adolescence, young people actively seek reassurance from others and these affiliative needs may interfere with health promoting behavior. For instance, the desire to maintain a relationship may outweigh the desire to use a condom for fear of conflict or abandonment ${ }^{[85,86]}$. These concerns may be particularly true of adolescent girls, who tend to emphasize interpersonal connection and relationships ${ }^{[87-90]}$. Thus, changing peer norms and emphasizing assertive communication are staples of current HIV prevention efforts.

Certain personality characteristics are also consistently linked to adolescent risk behavior. Sensation seeking and to a lesser extent impulsivity, are related to non-condom use, multiple partners and frequent sexual activity among young people ${ }^{[91,92]}$. High sensation seekers engage in more risk taking than low sensation seekers ${ }^{[93]}$. By contrast, placing value on one's health and academic achievement appear to protect against early pregnancy, sexual risk taking and alcohol and drug use ${ }^{[94]}$. Recent attention has been paid to the role of emotional regulation in promoting healthy behavior. Strong emotion regulation skills facilitate positive coping and appear to decrease risky behavior $^{[95]}$. HIV prevention programs are beginning to emphasize emotion regulation through learning and modeling techniques. Other personality characteristics are less amenable to change, but efforts are underway to find strategies to address various individual traits.

The environmental context of schools, communities, neighborhoods and society/culture, shapes adolescent sexual, substance use and problem behavior. Specific neighborhood characteristics, such as poverty, violence, drug trafficking and disorganization and stressful life events are related to early sexual debut, multiple sexual partners, premarital childbearing, more sexual activity and increased permissiveness ${ }^{[96-98]}$. Yet, other research reveals only modest effects of the environment on risk behavior ${ }^{[99,100]}$. Unfortunately, this level of intervention is the hardest and will require significant changes to policy and attitudes. 


\section{CONCLUSION}

The theory of human agency that has motivated most HIV prevention interventions to date has been the human capital model, which emphasizes education and training at the individual level. Priorities have increasingly focused, however, on producing more sustainable intervention outcomes by using supplementary approaches that emphasize social assets and capabilities. This has been conceived as the social capital model of human health ${ }^{[101,102]}$. Holtgrave and Crosby ${ }^{[103]}$ have found support for the impact of social capital on sexually transmitted diseases, particularly AIDS, using survey methodology and indicators of social capital based on constructs of social trust, the density of organizational activity and civic participation. Crosby, DiClemente, Wingood et al ${ }^{[104]}$ tracked membership and activity in social organizations by participants in an HIV prevention trial and then measured its predictive value in the study population's HIV and STD protective behavior. They found preliminary support for the social capital hypothesis in their study population of African American female adolescents. The implication of such research is that it may be possible to test an intervention that encourages and structures such participation and by consequence, improves the social capital of a group or community and thus their protective behavior.

Yet, there are strong indications from research involving adolescents that the human capital model is not as fully represented in interventions as commonly thought. For example, a review of a decade of adolescent STD/HIV behavioral interventions by Robin et al.$^{[105]}$ recommended more investigation of youth resiliency programs, which emphasize life skills, academic achievement, school bonding, general health risk reduction skills and co-involvement of teachers and parents. While they concluded that the most effective STI/HIV interventions were those that focused on specific protective behavioral skills, they also identified resiliency programs that may have produced results equal to these and perhaps of longer duration. One notable effort among adolescent sexual risk reduction projects to embody a more generalized approach is a sub-study conducted by investigators of the Gonorrhea Community Action Project. VanDevanter et al. ${ }^{[106]}$ report outcomes of an intervention to promote general preventive health care seeking, in which female adolescent participants significantly increased such behavior.

In a recent survey of HIV behavioral prevention experts, Copenhaver and Fisher ${ }^{[107]}$ found a consensus on the need for linking in interventions. This may involve incorporating mechanisms that actually train and direct individuals in establishing linkages with health services and social support. It also refers to interventions that seek to strengthen linkages between adolescents and parents and adolescents and supportive peers. These interventions seek to affect what many have called protective factors ${ }^{[108,110]}$. Social competency training and enhancement of positive assets can often be observed at the core of these interventions, in recognition that emotional dispositions and behavior are highly interdependent with the full range of social institutions: family and schools, community and government organizations and the health service system. Because of the prominence of emotional and social development issues in adolescent HIV prevention, these interventions may be at the frontier of controlling the epidemic in the coming decades until there is a vaccine or cure.

\section{ACKNOWLEDGEMENTS}

This research was funded in part by RO1 DA11875 from NIDA, RO1 AA11752 from NIAAA and R01 HD38458 from NICHD (Robert Malow, Principal Investigator).

\section{REFERENCES}

1. Centers for Disease Control and Prevention. HIV/AIDS Surveillance in Adolescents L265 slide series through 2003. Available from http://www.cdc.gov/HIV/graphics/adolesnt.htm.

2. Ellen, J.M., 2002. Adolescents and HIV. The Hopkins HIV Report. Available from http://www.hopkins-aids.edu/publications/ report/may02_6.html.

3. Centers for Disease Control and Prevention, May 2005. HIV/AIDS among Youth, pp. 1-4. Available from http://www.cdc.gov/hiv/pubs/facts/youth.pdf.

4. Malow, R.M., R. McMahon, D. Cremer, J.E. Lewis and S.M. Alferi, 1997. Psychosocial predictors of HIV risk among drug abusing adolescent offenders. Psychiatric Services, 48:185-187.

5. Malow, R.M., J. Dévieux, T.J. Jennings, B. Lucenko and S.C. Kalichman, 2001. Substance abusing adolescents at varying levels of HIV risk: Psychosocial characteristics, drug use and sexual behavior. J. Subst. Abuse Treat., 13:103-117.

6. Centers for Disease Control and Prevention, 1999. The CDC AIDS Community Demonstration Projects: a multi-site community-level intervention to promote HIV risk reduction. Am. J. Public Health, 89: 336-345.

7. Rolf, J., J. Nanda, J. Baldwin, A. Chandra and L. Thompson, 1990. Substance misuse and HIV/AIDS risks among delinquents: a prevention challenge. Intl. J. Addictions, 25: 33-559.

8. Tapert, S.F., G.A. Aarons, G.R. Sedlar and S.A. Brown, 2001. Adolescent substance use and sexual risk-taking behavior. J. Adolescent Health, 28: 181189. 
9. D’Angelo, L. and R. DiClemente, 1996. Sexually Transmitted Diseases Including Human Immunodeficiency Virus Infection. In R.J. DiClemente, W.B. Hansen and L.E. Ponton (Eds.), Handbook of Adolescent Health Risk Behavior, pp: 333-367. New York: Plenum Press.

10. Deas-Nesmith, D., K.T. Brady, R. White and S. Campbell, 1999. HIV-risk behaviors in adolescent substance abusers. J. Subst. Abuse Treat., 16: 169172.

11. Jemmott, J. and L. Jemmott, 2000. HIV Behavioral Interventions for Adolescents in Community Settings. In J.L. Peterson and R.J. DiClemente (Eds.), Handbook of HIV Prevention, pp: 103-127. New York: Kluwer Academic/Plenum Press.

12. DiClemente, R.J., M.M. Lanier, P.F. Horan and M. Lodico, 1991. Comparison of AIDS knowledge, attitudes and behaviors among incarcerated adolescents. A public school sample in San Francisco. Am. J. Public Health, 81: 628-630.

13. Hammett, T.M., 1998. Public Health/Corrections collaborations: Prevention and Treatment of HIV/AIDS, STDs and TB. Criminal Justice. National Institute of Justice Centers for Disease Control and Prevention Research in Brief, July 1998. Available from http://www.ncjrs.gov/pdffiles/169590.pdf.

14. Centers for Disease Control and Prevention. HIV/AIDS Education and Prevention Programs for Adults in Prisons and Jails and Juveniles in Confinement Facilities -United States, 1994 Vol. 45 / No. 13 MMWR 268-71, April 5, 1996, reported by T.M. Hammett and R. Widom. Available from http://www.cdc.gov/mmwr/PDF/wk/mm4513.pdf.

15. Teplin, L.A., A.A. Mericle, G.M. McClelland and K. Abram, 2003. HIV and AIDS risk behaviors in juvenile detainees: Implications for public health policy. A. J. Public Health, 93: 906-912.

16. American Academy of Pediatrics, 2001. Committee on Adolescence Health Care for Children and Adolescents in the Juvenile Correctional Care System. Pediatrics, 107: 799-803.

17. Seivewright, N. and C. Daly, 1997. Personality disorder and drug use: A review. Drug and Alcohol Rev., 16: 235-250.

18. McMahon, R., A. Kelley and K. Kouzekanani, 1993. Personality and coping styles in the prediction of dropout from treatment for cocaine abuse. J. Person. Assess., 61:147-155.

19. Mc Mahon, R., R. Malow, K. Kouzekanano and F. Penedo, 1998. Substance abuse problems, psychiatric severity and HIV risk in MCM-II Personality Subgroups. Psychol. Addictive Behav., 12: 3-13.

20. McMahon, R.C., R.M. Malow and T.E. Jennings, 2000. Personality, stress and social support in HIV risk prediction. AIDS and Behavior, 4: 399-410.
21. Edens, J.F., J.L. Skeem, K.R. Cruise and E. Cauffman, 2001. Assessment of "Juvenile Psychopathy" and its association with violence: A critical review. Behavioral Sciences and the Law, 19: 53-80.

22. Loper, A.B., S.J. Hoffschmidt and E. Ash, 2001. Personality features and characteristics of violent events committed by juvenile offenders. Behavioral Sciences and the Law, 19: 81-96.

23. Brooner, R.K., G.E. Bigelow, E. Strain and C.W. Schmidt, 1990. Intravenous drug abusers with antisocial personality disorder: Increased HIV risk behavior. Drug and Alcohol Dependence, 26: 39-44.

24. Brooner, R.K., L. Greenfield, C.W. Schmidt and G.E. Bigelow, 1993. Antisocial personality disorder and HIV infection among intravenous drug abusers. Am. J. Psychiat., 150: 53-58.

25. Compton, W.C., M.L. Smith, K.A. Cornish and D.L. Qualls, 1996. Factor structure of mental health measures. J. Person. Soc. Psychol., 71: 406-413.

26. Gill, K., D. Nolimal and T.J. Crowley, 1992. Antisocial personality disorder, HIV risk behavior and retention in methadone maintenance therapy. Drug and Alcohol Dependence, 30: 247-252.

27. Dinwiddie, S.H., L. Cottler, W. Compton and A.B. Abdallah, 1996. Psychopathology and HIV risk behaviors among injection drug users in and out of treatment. Drug and Alcohol Dependence, 43: 1-11.

28. Kelley, J.L. and N.M. Petry, 2000. HIV risk behaviors in male substance abusers with and without antisocial personality disorder. J. Subst. Abuse Treat., 19: 59-66.

29. Scheidt, D.M. and M. Windle, 1997. A comparison of alcohol typologies using HIV risk behaviors among alcoholic inpatients. Psychology of Addictive Behaviors, 11:3-17.

30. Abbott, P.J., S.B. Weller and S.R. Walker, 1994. Psychiatric disorders of opioid addicts entering treatment: Preliminary data. J. Addictive Disorders, 13: 1-11.

31. Compton, W.M., L.B. Cottler, E.L. Spitznagel, A.B. Abdallah and T. Gallagher, 1998. Cocaine users with antisocial personality disorder improve HIV risk behaviors as much as those without antisocial personality. Drug and Alcohol Dependence, 49:239247.

32. Compton, W. M., L.B. Cottler, A. Ben-Abdallah, R. Cunningham-Williams and E.L. Spitznagel, 2000. The effects of psychiatry comorbidity in response to an HIV prevention intervention. Drug and Alcohol Dependence, 58: 247-257.

33. Millon, T. and R. Davis, 1996. Disorders of Personality: DSM-IV and Beyond. New York: Wiley.

34. Bryan, A. and M.C. Stallings, 2002. A case control study of adolescent risky sexual behavior and its relationship to personality dimensions, conduct disorder and substance use. J. Youth and Adolescence, 31: 387-396. 
35. Bukstein, O.G., L.J. Glancy and U. Kaminer, 1992. Patterns of affective comorbidity in a clinical population of dually diagnosed adolescent substance abusers. J. Am. Acad. Child and Adolescent Psychiat., 31: 1041-1045.

36. Lucenko, B.A., R.M. Malow, J.G. Dévieux, M. Sanchez-Martinez and T. Jennings, 2003. Negative affect and HIV risk in alcohol and other drug (AOD) abusing adolescent offenders. J. Child and Adolescent Substance Abuse, 13: 1-17.

37. Donenberg, G.R. and M. Pao, 2005. Youths and HIV/AIDS: Psychiatry's role in a changing epidemic. J. Am. Acad. Child \& Adolescent Psychiat., 44: 728-747.

38. Rowe C.L., A. L. Howard, P.E. Greenbaum, C.E. Henderson, 2004. Impact of psychiatric comorbidity on treatment of adolescent drug Abusers. J. Subst. Abuse Treat., 26: 129-140.

39. Malow, R.M., R. Rosenberg, J. Dévieux, 2006. Prevention of Infection with Human Immunodeficiency Virus in Adolescent Substance Abusers. In: Adolescent Substance Abuse: Research and Clinical Advances (Eds. H.A. Liddle and C.L. Rowe), pp: 284-309. Cambridge University Press, Cambridge.

40. Whitmore, E.A. and P.D. Riggs, 2006. Developmentally Informed Diagnostic and Treatment Considerations in Comorbid Conditions. In: Adolescent Substance Abuse: Research and Clinical Advances (Eds. H.A. Liddle and C.L. Rowe), pp: 264-83. Cambridge University Press, Cambridge.

41. Gardner, W. and J. Herman, 1990. Adolescents' AIDS risk taking: A rational choice perspective. New Directions in Child Development, 50: 17-34.

42. Chambers, R.A., J.R. Taylor and M.N. Potenza, 2003. Developmental neurocircuitry of motivation in adolescence: A critical period of addiction vulnerability. Am. J. Psychiat., 160:1041-1052.

43. Shoveller, J. and W. Pietersma, 2002. Preventing HIV/AIDS risk behavior among youth. AIDS and Behavior, 6: 123-129.

44. Rotheram-Borus, M.J., 2000. Expanding the range of interventions to reduce HIV among adolescents. AIDS, 14 (Suppl. 1): S33-40.

45. Rotheram-Borus, M.J., Z. O'Keefe, R. Kracker and H.H. Foo, 2000. Prevention of HIV among adolescents. Prevent. Sci., 1: 15-30.

46. Malow, R., S. Gustman, D. Ziskind, R. McMahon and J. St. Lawrence, 1998. Evaluating HIV prevention interventions among drug abusers: Validity issues. J. HIV/AIDS Prevention \& Education for Adolescents and Children, 2: 21-40.

47. Fendrich, M. and Y. Xu, 1994. The validity of drug use reports from juvenile arrestees. The Intl. J. Addictions, 29: 971-985.
48. Magura, S. and S.Y Kang, 1996. Validity of selfreported drug use in high risk populations: A metaanalytical review. Substance Use \& Misuse, 3: 1131-1153.

49. Schachter, J., J. R. Moncada, R. Whidden, H. Shaw, G. Bolan, J. Burczak and H. Lee, 1995. Noninvasive tests for diagnosis of chlamydia trachomatis infection: Application of ligase chain reaction to first-catch urine specimens of women. J. Infect. Dis., 172: 1411-1414.

50. Quinn, T.C., C. Gaydos, M. Shepherd, L. Bobo, E.W. Hook 3rd, R. Viscidi and A. Rompalo, 1996. Epidemiologic and microbiologic correlates of chlamydia trachomatis infection in sexual partnerships. J. Am. Med. Assoc., 276: 1737-1742.

51. Zanis, D.A., A.T. McLellan and M. Randall, 1994. Can you trust patient self-reports of drug use during treatment? Drug and Alcohol Dependence, 35: 127132.

52. Newman, P.A. and M.A. Zimmerman, 2000. Gender differences in HIV-related sexual risk behavior among urban African American youth: A multivariate approach. AIDS Education \& Prevention, 12: 308-325.

53. Dévieux, J.G., R. Malow, J. Stein, T.E. Jennings, B. Lucenko, C. Averhart, S.C. Kalichman, 2002. Impulsivity and HIV risk among adjudicated alcohol and other drug (AOD) abusing adolescent offenders. AIDS Education and Prevention, 14 (Suppl. B): 24-35.

54. Leigh, B.C., 2002. Alcohol and condom use: a metaanalysis of event-level studies. Sexually Transmitted Disease, 29: 476-482.

55. Cohen, D., S. Spear, R. Scribner, P. Kissinger, K. Mason and J. Wildgen, 2000. "Broken windows" and the risk of gonorrhea. Am. J. Public Health, 90: 230-236.

56. Shoveller, J.A., J.L. Johnson, D.M. Savoy and W.A. Wia Pietersma, 2006. Preventing sexually transmitted infections among adolescents: an assessment of ecological approaches and study methods. Sex Education, 6:163-183.

57. Moos, R.H., 2003. Social contexts: Transcending their power and their fragility. Am. J. Community Psychol., 31: 1-13.

58. Moatti, J.P. and Y. Souteyrand, 2000. HIV/AIDS social and behavioural research: Past advances and thoughts about the future. Soc. Sci. Med., 50: 15191532.

59. Rapkin, B.D. and K.A. Dumont, 2000. Methods for identifying and assessing groups in health behavioral research. Addiction, 95 (Suppl. 3): 395-417.

60. Benotsch, E. and S. Kalichman, 2002. Preventing HIV and AIDS. In: Innovative Strategies for Promoting Health and Mental Health Across the Life Span. (Eds. L.A. Jason and D.S. Glenwick), pp: 205- 226. Springer Publishing Company, New York, N.Y. 
61. Plichta, S.B, C.S. Weisman, C.A. Nathanson, M.E. Ensminger and J.C. Robinson, 1992. Partnerspecific condom use among adolescent women clients of a family planning clinic. J. Adolescent Health, 13: 506-611.

62. Sanderson, C.A. and J.B. Jemmott, 1996. Moderation and mediation of HIV prevention interventions: Relationship status intentions and condom use among college students. Appl. Soc. Psychol., 26: 2076-2099.

63. Kim, N., B. Stanton, X. Li, K. Dickersin and J. Galbraith, 1997. Effectiveness of the 40 adolescent AIDS-risk reduction interventions: A quantitative review. J. Adolescent Health, 20: 204-215.

64. Masterman, P.W. and A.B. Kelly, 2003. Reaching adolescents who drink harmfully: Fitting intervention to developmental reality. J. Subst. Abuse Treat., 24: 347-345.

65. Fisher, J.D., W.A.Fisher, A.D. Bryan and S.J. Misovich, 2002. Information-motivation-behavioral skills model-based hiv risk behavior change intervention for inner-city high school youth. Health Psychol., 21: 177-186.

66. Mustanski, B., G. Donenberg and E. Emerson (In Press). I can use a condom, I just don't: The importance of motivation to prevent $\mathrm{HIV}$ in adolescent seeking psychiatric care. AIDS \& Behavior .

67. Donenberg, G.R., R. Paikoff and W. Pequegnat, 2006 Feb 8; [Epub ahead of print] Introduction to the Special Issue on Families, Youth and HIV: Family-Based Intervention Studies. Journal of Pediatric Psychology. PMID: 16467312

68. Perrino, T., A. Gonzalez-Soldevilla, H. Pantin and J. Szapocznik, 2000. The role of families in adolescent HIV prevention: A review. Clin. Child and Family Psychol. Rev., 3: 81-96.

69. Borawski, E.A., C.E. Levers-Landis, L.D. Lovegreen and E.S. Trapl, 2003. Parental monitoring, negotiated unsupervised time and parental trust: The role of perceived parenting practices in adolescent health risk behaviors. J. Adolescent Health, 33: 60-70.

70. Kotchick, B.A., A. Shaffer, R. Forehand, K.S. Miller, 2001. Adolescent sexual risk behavior: a multi-system perspective. Clin. Psychol. Rev., 21: 493-519.

71. McBride, C.K., R.L. Paikoff and G.N. Holmbeck, 2003. Individual and familial influences on the onset of sexual intercourse among urban African American adolescents. J. Consult. Clin. Psychol., 71: 159-167.

72. Miller, B.C., B. Benson and K.A. Galbraith, 2001. Family relationships and adolescent pregnancy risk: A research synthesis. Development. Rev., 21: 1-38.

73. Shaw, D. and R. Bell, 1993. Developmental theories of parental contributors to antisocial behavior. J. Abnormal Child Psychol., 21: 493-518.
74. Shaw, D.S. 2003. Innovative approaches and methods to the study of children's conduct problems. Soc. Develop., 12: 309-313.

75. Pettit, G.S., R.D. Laird, K.A. Dodge, J.E. Bates, M.M. Criss, 2001. Antecedents and behaviorproblem outcomes of parental monitoring and psychological control in early adolescence. Child Develop., 72: 583-98.

76. Paikoff, R.L., 1995. Early heterosexual debut: Situations of sexual possibility during the transition to adolescence. Am. J. Orthopsychiat., 65: 389-401.

77. Paikoff, R.L., S.H. Parfenoff, S.A. Williams and A. McCormick, 1997. Parenting, parent-child relationships and sexual possibility situations among urban African American preadolescents: Preliminary findings and implications for HIV prevention. J. Family Psychol., 11: 11-22.

78. Baumrind, D., 1987. A Developmental Perspective on Adolescent Risk-taking in Contemporary America. In: C.E. Irwin (Ed.), Adolescent Social Behavior and Health: New Directions for Child Development, pp: 93-125. San Francisco: JosseyBass.

79. Dilorio, C., E. Pluhar, L. Belcher, 2003. Parent-child communication about sexuality: A review of the literature from 1980-2001. J. HIV/AIDS Prevention \& Education for Adolescents \& Children, 5: 7-31.

80. Whitaker, D. and K.S. Miller, 2000. Parentadolescent discussions about sex and condoms: impact on peer influences of sexual risk behavior. J. Adolescent Res., 15: 251-273.

81. Pequegnat, W. and J. Szapocznik, 2000. The Role of Families in Preventing and Adapting to HIV/AIDS: Issues and Answers. In W. Pequegnat and J. Szapocznik (Eds.), Working with families in the era of HIV/AIDS. Thousand Oaks, CA: Sage Publications.

82. Kinsman, S.B., D. Romer, F.F. Furstenberg and D.F. Schwarz, 1998. Early sexual initiation: the role of peer norms. Pediatrics, 102: 1185-1192.

83. Prinstein M.J., J. Boergers, A. Spirito, 2001. Adolescents' and their friends' health-risk behavior: factors that alter or add to peer influence. J. Pediat. Psychol., 26: 287-298.

84. Santelli, J.S., J. Kaiser, L. Hirsch, A. Radosh, L. Simkin and S. Middlestadt, 2004. Initiation of sexual intercourse among middle school adolescents: the influence of psychosocial factors. J. Adolescent Health, 34: 200-208.

85. Ott, M.A., S.G. Millstein, B.L. Halpern-Felsher, 2004. Positive motivations for sex among male and female teens. Presented at the Annual Meeting of the Society for Adolescent Medicine, St. Louis.

86. Donenberg, G.R., E. Emerson, F.B. Bryant, H. Wilson and E. Weber-Shifrin, 2001. Understanding AIDS-risk behavior among adolescents in psychiatric care: links to psychopathology and peer relationships. J. Am. Acad.for Child Adolescent Psychiat., 40: 642-653. 
87. Welsh, D.P., C.M. Grello and M.S. Harper, 2003. When Love Hurts: Depression and Adolescent Romantic Relationships. In: P. Florsheim (Ed.), Adolescent Romantic Relations: Theory, Research and Practical Implications, pp: 185-212). Mahwah, NJ: Erlbaum.

88. Gilligan, C., 1982. In a different voice: Psychological theory and women's development. Cambridge, MA: Harvard University Press.

89. Gilligan, C., 1991. Women's Psychological Development: Implications for Psychotherapy. In C. Gilligan, A. Rogers and D. Tolman (Eds.), Women, girls and psychotherapy: Reframing resistance. Binghamton, NY: Haworth Press.

90. Donenberg, G., F. Bryant, E. Emerson, H. Wilson and K. Pasch, 2003. Tracing the roots of early sexual debut among adolescents in psychiatric care. J. Am. Acad. Child Adolescent Psychiat., 42: 594-608.

91. Eyre, S.L., C. Auerswald, V. Hoffman and S.G. Millstein, 1998. Fidelity management: AfricanAmerican adolescents' attempts to control the sexual behavior of their partners. J. Health Psychol., 3: 393406.

92. Brown, L.K., R.J. DiClemente and T. Park, 1992. Predictors of condom use in sexually active adolescents. J. Adolescent Health, 13: 651-657.

93. Zuckerman, M., 1994. Behavioral Expressions and Biosocial Bases of Sensation Seeking. New York: Cambridge University Press.

94. Donohew, L., R. Zimmerman, P.S. Cupp, S. Novak, S. Colon and R. Abell, 2000. Sensation seeking, impulsive decision making and risky sex: implications for risk-taking and design interventions. Personality and Individual Differences, 28: 10791091.

95. Rosengard, C., N.E. Adler, S.G. Millstein, J.E. Gurvey and J.M. Ellen, 2004. Perceived STD risk, relationship and health values in adolescents/ delaying sexual intercourse with new partners. Sexually Transferred Infections, 80: 130-137.

96. DiClemente, R.J., G.M. Wingood, R. Crosby et al., 2001. A prospective study of psychological distress and sexual risk behavior among African American adolescent females. Pediatrics, 108: 1-6.

97. Brooks-Gunn, J., P. Duncan, P.K. Klebanov and N. Sealand, 1993. Do neighborhoods influence child and adolescent development. Am. J. Sociol., 99: 353-395.

98. Ramirez-Valles, J., M.A. Zimmerman and L. Juarez, 2002. Gender differences of neighborhood and social control processes: a study of the timing of first intercourse among low-achieving, urban, African American youth. Youth Sociol., 33: 418-441.
99. Sucoff, C.A. and D.M. Upchurch, 1998. Neighborhood context and the risk of childbearing among metropolitan-area black adolescents. Am. Sociol. Rev., 63: 571-585.

100.Blum, R.W., T. Beuhring, M.L. Shew, L.H. Bearinger, R.E. Sieving, M.D. Resnick, 2000. The effects of race/ethnicity, income and family structure on adolescent risk behaviors. Am. J. Public Health, 90:1879-1884.

101. Santelli, J., R. Lowry, N. Brener and L. Robin, 2000. The association of sexual behaviors with socioeconomic status, family structure and race/ethnicity among US adolescents. Am. J. Public Health, 90: 1582-1588.

102. Mechanic, D., 2000. Rediscovering the social determinants of health. Health Affairs, 19: 269-76.

103. Veenstra, G., 2000. Social capital, SES and health: An individual-level analysis. Soc. Sci. Med., 50: 619-29.

104.Holtgrave, D.R. and R.A. Crosby, 2003. Social capital, poverty and income inequality as predictors of gonorrhoea, syphilis, chlamydia and AIDS case rates in the United States. Sexually Transmitted Infection, 79: 62-64.

105. Crosby, R.A., R.J. DiClemente, G.M. Wingood et al., 2002. Participation by African-American adolescent females in social organizations: associations with HIV-protective behaviors. Ethnicity and Disease, 12: 186-192.

106. Robin, L., P. Dittus, D. Whitaker, K. Crosby, J. Ethier, C. Mezoff, K. Miller and K. Pappas-Deluca, 2004. Behavioral interventions to reduce incidence of HIV, STD and Pregnancy among adolescents: A decade in review. J. Adolescent Health, 34: 3-26.

107. VanDevanter, N.L., P. Messeri, S.E. Middlestadt, A. Bleakley, C.R. Merzel, M. Hogben, R. Ledsky, C.K. Malotte, R.M. Cohall, T.L. Gift and J.S. St. Lawrence, 2005. A community-based intervention designed to increase preventive health care seeking among adolescents: The gonorrhea community action project. Am. J. Public Health, 95: 331-337.

108. Copenhaver, M.M. and J.D. Fisher, 2006. Experts outline ways to decrease the decade-long yearly rate of 40,000 new HIV infections in the US. AIDS and Behavior, 10: 105-114.

109. Griffin, K.W., G.J. Botvin and T.R. Nichols, 2006. Effects of a school-based drug abuse prevention program for adolescents on HIV risk behavior in young adulthood. Prevent. Sci., 7: 103-12.

110. Catalano, R.F., J.D. Hawkins, M.L. Berglund, J.A. Pollard and M.W. Arthur, 2002. Prevention science and positive youth development: Competitive or cooperative frameworks? J. Adolescent Health, 31 (Suppl. 6): 230-9. 